\title{
The case for intraocular delivery of PPAR agonists in the treatment of diabetic retinopathy
}

\author{
Maxwell P Treacy ${ }^{1 *}$ and Tara P Hurst ${ }^{2}$
}

\begin{abstract}
Background: Systemic therapeutics targeting the peroxisome proliferator-activated receptors have been found to be beneficial in the treatment of diabetic retinopathy. In this paper, we provide a rationale for the use of these therapeutics as intraocular agents. In addition, we introduce the peroxisome proliferator-activated receptors and describe their functions in response to the drugs.

Discussion: Based on the evidence of large-scale clinical studies investigating the systemic administration of fenofibrate, this ligand for peroxisome proliferator-activated receptor-a is potentially a good candidate for intraocular delivery. Here, we describe the mechanisms by which it might be acting to improve diabetic retinopathy, its relative safety and we speculate on how it could be developed for intraocular delivery.
\end{abstract}

Summary: In this paper, we provide a rationale for the further investigation of peroxisome proliferator-activated receptor-a agonists as intraocular agents for the treatment of diabetic retinopathy.

Keywords: Diabetes, Diabetic retinopathy, Intraocular, Fenofibrate, TZDs, PPARs

\section{Background}

Diabetic retinopathy (DR) is a leading cause of blindness in adults, with some degree of DR occurring in nearly all type 1 diabetics and in the majority of type 2 diabetics [1]. Hitherto, it was thought that the only way to prevent the development and progression of DR was by tight control of blood sugar, plasma lipids and blood pressure [1]. However, it has since been shown that treatment of type 2 diabetics with lipid-lowering fenofibrates results in a significant reduction in the progression of DR which may be unrelated to any effect on plasma lipid levels $[2,3]$. A related class of compounds, the thiazolidinediones (TZDs), have been found to reduce progression to DR in at least one clinical trial [4]. Thus far, the beneficial effect of PPAR agonists on the retina has been observed following systemic delivery for the treatment of diabetic patients. It is our contention that the intraocular delivery of these agonists could specifically ameliorate DR.

Fibrates and TZDs are agonists for two isoforms of nuclear receptor superfamily members, the peroxisome proliferator-activated receptors (PPARs) $\alpha$ and $\gamma$,

\footnotetext{
* Correspondence: max@treacy.ie

'Royal Victoria Eye and Ear Hospital, Adelaide Road, Dublin 2, Dublin, Ireland Full list of author information is available at the end of the article
}

respectively. PPARs are localised to the nucleus, where they interact with other proteins involved in gene expression, including various co-activator and co-repressor proteins [5]. In order for PPARs to induce gene expression, they must also interact with their co-activator, the retinoic X receptor (RXR), and then bind to a PPAR response element (PPRE) in a given gene Figure 1 [6-9]. PPARs modulate the expression of numerous genes, including those involved in lipid metabolism, adipogenesis, inflammatory signalling and oxidative stress [9-11], in a tissue-dependent manner [12]. Importantly, PPARs also regulate the expression of themselves via a positive feedback mechanism $[13,14]$ or through a co-operative system with other transcription factors $[15,16]$.

PPARs are generally considered to be inactive until bound by a ligand [17]. Both endogenous ligands and synthetic agonists have been described for PPAR $\alpha$ and $\gamma$. Endogenous ligands include fatty acids and lipid metabolites, such as prostaglandins and leukotrienes [18-21]. Interestingly, prostaglandins and leukotrienes are also known to be mediators of inflammation and oxidative stress [22,23]. Synthetic agonists for the different PPAR isoforms are similar in terms of chemical structure and molecular mass; in fact, there are several known dual agonists that activate both PPAR $\alpha$ and PPAR $[24,25]$.

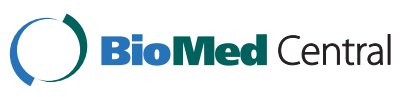




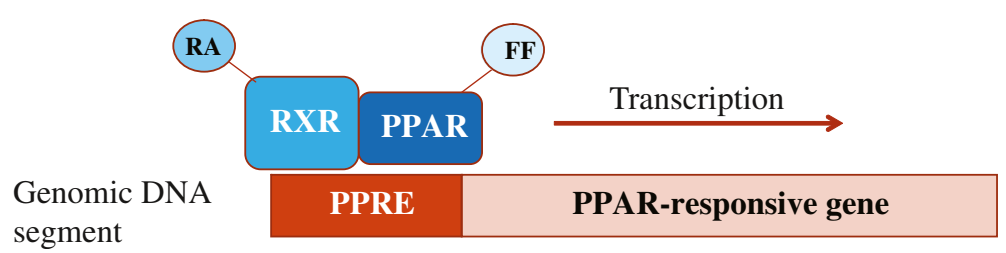

Figure 1 Agonist-bound PPARs induce gene expression. Activated PPARs must first associate with their co-receptor, retinoid X receptor (RXR), in order to modulate transcription of specific genes. RXR binds to its ligand, retinoic acid, and interacts with PPAR bound to an agonist (e.g. fibrates). Together, RXR and PPAR can then bind to a consensus sequence of nucleotides, known as the PPAR response element (PPRE). PPAR and RXR binding triggers expression of a responsive gene. Abbreviations: RA, retinoic acid, FF, fenofibrate.

The aforementioned synthetic PPAR agonists, fibrates and TZDs, are structurally very similar. However, research shows that fenofibrate specifically acts via PPAR $\alpha$ [26], whilst TZDs are known to specifically activate PPAR $\gamma$ [27-30]. Further, PPAR $\alpha$ and PPAR $\gamma$ are also known to have distinct physiological roles $[9,31]$. While PPAR $\alpha$ increases the uptake and beta-oxidation of fatty acids, as well as reduces the synthesis and secretion of triglycerides, PPAR $\gamma$ specifically induces adipogenesis and stimulates triglyceride storage [12]. PPARY is thought to improve insulin sensitivity via its stimulatory effects on GLUT4 and adiponectin [31]. Although both PPAR $\alpha$ and PPAR $\gamma$ have been found to inhibit inflammation, they do so within different cell types via distinct targets $[10,12]$. Compared to PPAR $\alpha$, PPAR $\gamma$ has broader anti-inflammatory activity due to targeting numerous transcription factors within more cell types than PPAR $\alpha$ [12]. In particular, PPAR $\gamma$ has been found to function as an inhibitor of monocyte/macrophage function by blocking pro-inflammatory signals [32-34]. To date, PPAR agonists have been clinically utilised for the treatment of diabetes and dyslipidaemia due to their beneficial effects on insulin sensitivity and lipid metabolism.

The PPARY agonists, TZDs, are prescribed for lowering blood glucose levels [35] but it is uncertain whether they could also reduce DR progression since there are no randomised clinical trials. However, there has been one retrospective review of diabetic patients receiving rosiglitazone which revealed a reduction in development of proliferative DR [4], although this paper was criticised because of unmatched controls [36]. TZDs have also been trialled in animal models and were found to reduce choroidal neovascularisation [37]. Interestingly, the TZDs in this study were given by intraocular injection, suggesting that this delivery route of PPAR agonists might also be efficacious in humans [37]. Against the use of TZDs in the treatment of DR are the findings that systemic administration of troglitazone in humans was associated with increased vascular endothelial growth factor (VEGF) expression [38] and with an increased risk of diabetic macular oedema (DMO) [39]. Although the latter has been challenged by subsequent studies [40], questions remain about the overall safety and efficacy of TZDs $[9,41,42]$. In addition to TZDs, newer PPAR $\gamma$ modulators are being developed which could have enhanced safety profiles $[9,43]$. Further scientific and clinical studies are needed to clarify the role of PPAR $\gamma$ in DR and to determine whether treatment with TZDs or novel PPAR $\gamma$ agonists would be beneficial. Currently, no PPAR $\gamma$ agonists are known to reduce DR progression to the same extent observed with fibrates.

\section{Discussion}

In the UK, under the NICE guidelines, fibrates are prescribed as a first-line therapy for diabetics with high serum triglycerides and are often given in combination with statins [35]. Recently, two large, randomised clinical trials showed an important secondary benefit of systemically-delivered fenofibrate on DR in type 2 diabetics. In the FIELD study, fenofibrate $(200 \mathrm{mg} /$ day $)$ taken over five years reduced the need for laser photocoagulation to treat diabetic maculopathy by $36 \%$ and proliferative retinopathy by $32 \%$ [2]. Similar results were observed in the ACCORD Eye Study, wherein the use of fenofibrate along with simvastatin reduced progression of DR by $40 \%$ compared to simvastatin alone [3], with DR progression defined as a deterioration by three steps on the ETDRS severity scale. Importantly, in the FIELD study in particular, this benefit was independent of plasma lipid levels [2]. In addition, in both the FIELD and ACCORD studies, the benefit of fenofibrate was independent of glycaemic control. These findings could suggest that fenofibrate is having local effects within the eye not necessarily related to systemic metabolism.

Diabetic retinopathy is characterised by microangiopathy, which is thought to be caused by oxidative stress, advanced glycation end-products (AGEs), inflammatory mediators and endothelial cell death [44-46]. The beneficial effects of fenofibrate observed in the FIELD and ACCORD Eye studies could be due to reduced oxidative stress and inflammation, as well as effects on vascular function. Several studies have analysed the pharmacological mechanisms of fenofibrate individually. For example, fenofibrate has been shown to reduce circulating 
markers of oxidative stress in dyslipidaemic patients [47]. It has also been found to prevent inflammation by blocking AGE-induced NF- $\mathrm{kB}$ activation in animal models [48]. Fenofibrate has been found to ameliorate vascular function, improving blood flow in diabetics [49]. One recent study investigated the combined effects of fenofibrate on oxidative stress, inflammation and vascular tone in an animal model of diabetes [50]. This study found that fenofibrate improved vascular relaxation and increased expression of the antioxidant enzymes, superoxide dismutase and catalase [50]. Interestingly, they also observed a decrease in the level of a proinflammatory marker, myeloperoxidase (MPO) [50]. Importantly, a comprehensive screen of donated human retinal pigment epithelia (RPE) revealed that PPAR $\alpha$ (the receptor for fenofibrate) was highly expressed while PPAR $\gamma$ was absent from the RPE [51]. Further, laboratory studies using human RPE cells under hyperglycaemic conditions found that fenofibrate reduced RPE monolayer permeability [52] via blocking activation of AMP-activated protein kinase (AMPK) [53,54] and the reduction in permeability was dose-dependent, indicating that intraocular delivery of fenofibrate could be highly efficacious. In summary, there is an expanding molecular basis for the positive effects of fenofibrate observed in the FIELD and ACCORD Eye studies.

Compared to other currently available PPAR agonists, fenofibrate appears to have a better safety profile. Fenofibrate has been prescribed for many years and is generally well-tolerated, with only $2 \%$ of patients discontinuing use due to side-effects [55]. There have been concerns that long-term use of fenofibrates might be associated with an increased risk of cardiovascular disease, particularly in those with renal impairment [56]. However, assessment of data from the FIELD study did not support this, providing further evidence for the safety profile of fenofibrate [56]. Given the findings of the large-scale FIELD and ACCORD Eye studies, fenofibrate has been found to reduce progression of DR and has not been associated with drug safety issues, making it a good candidate for potential intraocular delivery.

To our knowledge, the intraocular delivery of fenofibrate has not yet been examined. Therefore, animal and clinical trials are needed to determine if this delivery method would be suitable for the prevention and treatment of DR. The pharmacokinetics of these agonists in the eye is unknown. To date, fenofibrate has been formulated for oral delivery and is converted by esterases into the active compound, fenofibric acid [57]. Fenofibric acid has a half-life of $16 \mathrm{~h}$ and reaches a steady-state level in the circulation within five days of the commencement of treatment [55]. Given this need for esterase conversion, the delivery of a pre-activated form of fenofibrate into the eye could be more effective. One example of such a fenofibrate derivative is ABT-335, which is a choline salt of fenofibric acid and does not require esterase processing [55]. Such a readily bioactive drug could be better suited to intraocular delivery than the fenofibrate parent compound.

Should treatment with fenofibrate alone prove beneficial in the management of DR, combination therapies could then be examined. For example, it is now widespread practice to treat DMO with intraocular injections of anti-VEGF therapeutics [58-62]. While treatment with anti-VEGF is effective, it requires frequent injections $[58,62-64]$. This represents a burden on the patients and the healthcare delivery services. It is conceivable that intraocular anti-VEGF therapies could be combined with fenofibrate in the same injection, which might reduce the frequency of injections and therefore represent an improved treatment strategy. Whether the combination of fenofibrate and anti-VEGF agents will be viable for co-administration would need to be examined.

The goal of this paper is to provide a rationale for the intraocular injection of PPAR agonists, particularly fenofibrate or its derivatives, and to encourage further research in this area.

\section{Summary}

- The ACCORD and FIELD Eye studies showed a significant beneficial effect on DR in diabetics treated with systemic fenofibrates.

- There is evidence from one study that intraocular delivery of TZDs is effective in treating CNV in an animal model, suggesting that PPAR agonists can be biologically active in the eye.

- Relative expression levels in the RPE suggest that PPAR $\alpha$ agonists might be more beneficial than PPARY agonists for the treatment of DR.

- There is emerging molecular evidence for the beneficial effects of PPAR $\alpha$ agonists in the treatment of DR that goes beyond an improvement in plasma lipid levels.

- The commonplace treatment of DR with intraocular anti-VEGF agents could be used to facilitate PPAR $\alpha$ agonist delivery. In other words, fibrates could be delivered concurrently with anti-VEGF using the same injection.

\section{Abbreviations}

AGE: Advanced glycation end-products; CNV: Choroidal neovascularisation; DMO: Diabetic macular oedema; DR: Diabetic retinopathy; NF-KB: Nuclear factor-KB; PPAR: Peroxisome proliferator-activated receptor; PPRE: PPAR response element; RPE: Retinal pigment epithelium; RXR: Retinoic X receptor; TZDs: Thiazolidinediones; VEGF: Vascular endothelial growth factor.

\section{Competing interests}

The authors declare that they have no competing interests. 


\section{Authors' contributions}

The authors contributed equally to the analysis, design and writing of the article.

\section{Authors' information}

Dr. Maxwell Treacy is an engineer and trainee in ophthalmology. Dr. Tara Hurst is a biochemist, specialising in the innate immune response and viral modulation of cellular pathways.

\section{Acknowledgements}

The authors would like to thank Grace Hurst for critically reviewing the manuscript.

\section{Author details}

${ }^{1}$ Royal Victoria Eye and Ear Hospital, Adelaide Road, Dublin 2, Dublin, Ireland. ${ }^{2}$ School of Science and Technology, Nottingham Trent University, Clifton Lane, Nottingham NG11 8NS, United Kingdom.

Received: 25 May 2012 Accepted: 29 August 2012

Published: 2 September 2012

\section{References}

1. Mohamed Q, Gillies MC, Wong TY: Management of diabetic retinopathy: a systematic review. J Am Med Assoc 2007, 298:902-916

2. Keech AC, Mitchell P, Summanen PA, O'Day J, Davis TM, Moffitt MS, Taskinen MR, Simes RJ, Tse D, Williamson E, Merrifield A, Laatikainen LT, d'Emden MC, Crimet DC, O'Connell RL, Colman PG: FIELD study investigators. Effect of fenofibrate on the need for laser treatment for diabetic retinopathy (FIELD study): a randomised controlled trial. Lancet 2007, 370:1687-1697.

3. ACCORD Study Group and ACCORD Eye Study: Effects of medical therapies on retinopathy progression in Type 2 Diabetes. N Engl J Med 2010, 363:233-244

4. Shen LQ, Child A, Weber GM, Folkman J, Aiello LP: Rosiglitazone and Delayed Onset of Proliferative Diabetic Retinopathy. Arch Ophthalmol 2008, 126:793-799.

5. Kota BP, Huang THW, Roufogalis BD: An overview on biological mechanisms of PPARs. Pharmacol Res 2005, 51:85-94.

6. Issemann I, Prince RA, Tugwood JD, Green S: The retinoid X receptor enhances the function of the peroxisome proliferator activated receptor. Biochimie 1993, 75:37-47.

7. Schoonjans K, Peinado-Onsurbe J, Lefebvre AM, Heyman RA, Briggs M, Deeb S, Staels B, Auwerx J: PPARa and PPARy activators direct a distinct tissue-specific transcriptional response via a PPRE in the lipoprotein lipase gene. EMBO J 1996, 15:5336-5348.

8. Varanasi U, Chu R, Huang Q, Castellon R, Yeldandi AV, Reddy JK: Identification of a peroxisome proliferator-responsive element upstream of the human peroxisomal fatty acyl coenzyme A oxidase gene. J Biol Chem 1996, 271:2147-2155.

9. Ciudin A, Hernández C, Simó R: Update on cardiovascular safety of PPARgamma agonists and relevance to medicinal chemistry and clinical pharmacology. Curr Top Med Chem 2012, 12:585-604.

10. Varga T, Czimmerer Z, Nagy L: PPARs are a unique set of fatty acid regulated transcription factors controlling both lipid metabolism and inflammation. Biochim Biophys Acta 2011, 1812:1007-1022.

11. Michalik L, Auwerx J, Berger JP, Chatterjee VK, Glass CK, Gonzalez FJ, Grimaldi PA, Kadowaki T, Lazar MA, O'Rahilly S, Palmer CN, Plutzky J, Reddy JK, Spiegelman BM, Staels B, Wahli W: International Union of Pharmacology. LXI. Peroxisome Proliferator-Activated Receptors. Pharmacol Rev 2006, 58:726-741.

12. Moraes L, Piqueras L, Bishop-Bailey D: Peroxisome proliferator-activated receptors and inflammation. Pharmacol Ther 2006, 110:371-385.

13. Lazar MA: Becoming fat. Genes Dev 2002, 16:1-5.

14. Li Y, Lazar MA: Differential gene regulation by PPARY Agonist and constitutively active PPARy2. Mol Endocrinol 2002, 16:1040-1048.

15. Aleshin S, Grabeklis S, Hanck T, Sergeeva M, Reiser G: Peroxisome proliferator-activated receptor (PPAR)- $\gamma$ positively controls and PPARa negatively controls cyclooxygenase- 2 expression in rat brain astrocytes through a convergence on PPAR $\beta / \delta$ via mutual control of PPAR expression levels. Mol Pharmacol 2009, 76:414-424.
16. Kim JE, Chen J: Regulation of peroxisome proliferator-activated receptor$\gamma$ activity by mammalian target of rapamycin and amino acids in adipogenesis. Diabetes 2004, 53:2748-2756.

17. Green S, Tugwood JD, Issemann I: The molecular mechanism of peroxisome proliferator action: a model for species differences and mechanistic risk assessment. Toxicol Lett 1992, 64/65:131-139.

18. Forman BM, Chen J, Evans RM: Hypolipidemic drugs, polyunsaturated fatty acids, and eicosanoids are ligands for peroxisome proliferatoractivated receptors $a$ and $\delta$. PNAS 1997, 94:4312-4317.

19. Kliewer SA, Sundseth SS, Jones SA, Brown PJ, Wisely GB, Koble CS, Devchand P, Wahli W, Willson TM, Lenhard JM, Lehmann JM: Fatty acids and eicosanoids regulate gene expression through direct interactions with peroxisome proliferator-activated receptors a and $ү$. PNAS 1997, 94:4318-4323.

20. Krey G, Braissant O, L'Horset F, Kalkhoven E, Perroud M, Parker MG, Wahli W: Fatty acids, eicosanoids, and hyoplipidemic agents identified as ligands of peroxisome proliferator-activated receptors by coactivator-dependent receptor ligand assay. Mol Endocrinol 1997, 11:779-791.

21. Wilson TM, Lehmann JM, Kliewer SA: Discovery of ligands for the nuclear peroxisome proliferator-activated receptors. Ann N Y Acad Sci 1996, 804:276-83.

22. Stables MJ, Gilroy DW: Old and new generation lipid mediators in acute inflammation and resolution. Prog Lipid Res 2011, 50:35-51.

23. Ullery JC, Marnett LJ: Protein modification by oxidized phospholipids and hydrolytically released lipid electrophiles: investigating cellular responses. Biochim Biophys Acta 2012, 1818:2424-2435.

24. Tonstad S, RetterstøI K, Ose L, Ohman KP, Lindberg MB, Svensson M: The dual peroxisome proliferator-activated receptor $\alpha / \gamma$ agonist tesaglitazar further improves the lipid profile in dyslipidemic subjects treated with atorvastatin. Metabolism Clinical and Experimental 2007, 56:1285-1292.

25. Cavender MA, Lincoff AM: Therapeutic potential of aleglitazar, a new dual PPAR- $a / \gamma$ agonist: implications for cardiovascular disease in patients with diabetes mellitus. Am J Cardiovasc Drugs 2010, 10:209-216

26. Guerre-Millo M, Gervois P, Raspé E, Madsen L, Poulain P, Derudas B, Herbert JM, Winegar DA, Willson TM, Fruchart JC, Berge RK, Staels B: Peroxisome proliferator-activated receptor a activators improve insulin sensitivity and reduce adiposity. J Biol Chem 2000, 275:16638-16642.

27. Elbrecht A, Chen Y, Cullinan CA, Hayes N, Leibowitz M, Moller DE, Berger J: Molecular Cloning, Expression and Characterization of Human Peroxisome Proliferator Activated Receptors $\gamma 1$ and $\gamma 2$. Biochem Biophys Res Commun 1996, 224:431-437.

28. Johnson TE, Holloway MK, Vogel R, Rutledge SJ, Perkins JJ, Rodan GA, Schmidt A: Structural requirements and cell-type specificity for ligand activation of peroxisome proliferator-activated receptors. J Steroid Biochem Mol Biol 1997, 63:1-8.

29. Staels B, Schoonjans K, Fruchart JC, Auwerx J: The effects of fibrates and thiazolidinediones on plasma triglyceride metabolism are mediated by distinct peroxisome proliferator activated receptors (PPARs). Biochimie 1997, 79:95-99.

30. Young PW, Buckle DR, Cantello BCC, Chapman H, Clapham JC, Coyle PJ, Haigh D, Hindley RM, Holder JC, Kallender H, Latter AJ, Lawrie KWM, Mossakowska D, Murphy GJ, Cox LR, Smith SA: Identification of high affinity binding sites for the insulin sensitizer rosiglitazone (BRL-49653) in rodent and human adipocytes using a radioiodinated ligand for peroxisome proliferator-activated receptor. J Pharmacol Exp Ther 1998, 284:751-759.

31. Ferré $P$ : The biology of peroxisome proliferator-activated receptors: relationship with lipid metabolism and insulin sensitivity. Diabetes 2004 53:\$43-\$50

32. Jiang C, Ting AT, Seed B: PPAR- $\gamma$ agonists inhibit production of monocyte inflammatory cytokines. Nature 1998, 391:82-86.

33. Ricote M, Li AC, Willson TM, Kelly CJ, Glass CK: The peroxisome proliferator-activated receptor- $\gamma$ is a negative regulator of macrophage activation. Nature 1998, 391:79-82.

34. Hevener AL, Olefsky JM, Reichart D, Nguyen MT, Bandyopadyhay G, Leung HY, Watt MJ, Benner C, Febbraio MA, Nguyen AK, Folian B, Subramaniam S, Gonzalez FJ, Glass CK, Ricote M: Macrophage PPARY is required for normal skeletal muscle and hepatic insulin sensitivity and full antidiabetic effects of thiazolidinediones. J Clin Invest 2007, 117:1658-1669.

35. NICE Guideline CG87: Type 2 Diabetes - newer agents (partial update of CG66) (CG87); http://www.nice.org.uk/CG87. 
36. Shen LQ, Child A, Weber GM, Folkman J, Aiello LP: Rosiglitazone and Delayed Onset of Proliferative Diabetic Retinopathy. Arch Ophthalmol 2008, 126:793-799.

37. Chu SH, Li AH: Association of proliferative diabetic retinopathy with insulin use and microalbuminuria. Arch Ophthalmol 2010, 128:147-148.

38. Murata T, He S, Hangai M, Ishibashi T, Xi XP, Kim S, Hsueh WA, Ryan SJ, Law RE, Hinton DR: Peroxisome proliferator-activated receptor- $\gamma$ ligands inhibit choroidal neovascularization. Invest Ophthalmol Vis Sci 2000 41:2309-2317

39. Emoto M, Anno T, Sato Y, Tanabe K, Okuya S, Tanizawa Y, Matsutani A, Oka Y: Troglitazone Treatment Increases Plasma Vascular Endothelial Growth Factor in Diabetic Patients and Its mRNA in 3 T3-L1 Adipocytes. Diabetes 2001, 50:1166-1170.

40. Fong DS, Contreras R: Glitazone use associated with diabetic macular edema. Am J Ophthalmol 2009, 147:583-586.

41. Ambrosius T, Danis RP, Goff DC Jr, Greven CM, Gerstein HC, Cohen RM, Riddle MC, Miller ME, Buse JB, Bonds DE, Peterson KA, Rosenberg YD, Perdue LH, Esser BA, Seaquist LA, Felicetta JV, Chew EY: ACCORD Study Group: Lack of association between thiazolidinediones and macular edema in type 2 diabetes. Arch Ophthalmol 2010, 128:312-318.

42. Palee S, Chattipakorn S, Phrommintikul A, Chattipakorn N: PPARy activator, rosiglitazone: Is it beneficial or harmful to the cardiovascular system? World Journal of Cardiology 2011, 3:144-152.

43. Rachek LI, Yuzeforych LV, Ledoux SP, Julie NL, Wilson GL: Troglitazone, but not rosiglitazone, damages mitochondrial DNA and induces mitochondrial dysfunction and cell death in human hepatocytes. Toxicol Appl Pharmacol 2009, 240:348-354.

44. Carpino PA, Goodwin B: Diabetes area participation analysis: a review of companies and targets described in the 2008-2010 patent literature. Expert Opin Ther Pat 2010, 20:1627-1651.

45. Bhatwadekar AD, Glenn JV, Li G, Curtis TM, Gardiner TA, Stitt AW: Advanced glycation of fibronectin impairs vascular repair by endothelial progenitor cells: implications for vasodegeneration in diabetic retinopathy. Investigative Ophthalmology \& Vision Science 2008, 49:1232-1241.

46. Peppa M, Uribarri J, Vlassara H: Glucose, advanced glycation end products, and diabetes complications: what is new and what works. Clinical Diabetes 2003, 4:186-187.

47. Miranda S, González-Rodríguez Á, García-Ramírez M, Revuelta-Cervantes J, Hernández C, Simó R, Valverde AM: Beneficial effects of fenofibrate in retinal pigment epithelium by the modulation of stress and survival signaling under diabetic conditions. J Cell Physiol 2012, 227:2352-2362.

48. Dong Y, Steffen BT, Cao J, Tsai AK, Ordovas J, Straka R, Zhou X, Kabagambe E, Hanson NQ Arnett D, Tsai MY: Effects of fenofibrate on plasma oxidized LDL and 8-isoprostane in a sub-cohort of GOLDN participants. Atherosclerosis 2011, 214:422-425.

49. Tomizawa A, Hattoria Y, Inoueb T, Hattoria S, Kasaia K: Fenofibrate suppresses microvascular inflammation and apoptosis through adenosine monophosphate-activated protein kinase activation. Metabolism 2011, 60:513-522.

50. Koh KK, Quon MJ, Rosenson RS, Chung WJ, Han SH: Vascular and metabolic effects of treatment of combined hyperlipidemia: focus on statins and fibrates. Int J Cardiol 2008, 124:149-159.

51. Olukman M, Sezer ED, Ulker S, Sozmen EY, CInar GM: Fenofibrate treatmen enhances antioxidant status and attenuates endothelial dysfunction in streptozotocin-induced diabetic rats. Exp Diabetes Res 2010, Article ID 828531

52. Dwyer MA, Kazmin D, Hu P, McDonnell DP, Malek G: Nuclear receptor atlas of human retinal pigment epithelial cells: potential relevance to agerelated macular degeneration. Mol Endocrinol 2011, 25:360-372.

53. Trudeau K, Roy S, Guo W, Hernández C, Villarroel M, Simó R, Roy S: Fenofibric acid reduces fibronectin and collagen type IV overexpression in human retinal pigment epithelial cells grown in conditions mimicking the diabetic milieu: functional implications in retinal permeability. Invest Ophthalmol Vis Sci 2011, 52:6348-6354.

54. Villarroel M, Garcia-Ramírez M, Corraliza L, Hernández C, Simó R: Fenofibric acid prevents retinal pigment epithelium disruption induced by interleukin- $1 \beta$ by suppressing AMP-activated protein kinase (AMPK) activation. Diabetologia 2011, 54:1543-1553.

55. Kim J, Ahn JH, Kim JH, Yu YS, Kim HS, Ha J, Shinn SH, Oh YS: Fenofibrate regulates retinal endothelial cell survival through the AMPK signal transduction pathway. Exp Eye Res 2007, 84:886-893.
56. Filippatos T, Milionis HJ: Treatment of hyperlipidaemia with fenofibrate and related fibrates. Expert Opin Investig Drugs 2008, 17:1599-1614.

57. Ting RD, Keech AC, Drury PL, Donoghoe MW, Hedley J, Jenkins AJ, Davis TM, Lehto S, Celermajer D, Simes RJ, Rajamani K, Stanton K: FIELD Study Investigators: Benefits and Safety of Long-Term Fenofibrate Therapy in People With Type 2 Diabetes and Renal Impairment: The FIELD Study. Diabetes Care 2012, 35:218-225

58. Pubchem CID 3339: Fenofibrate - Compound Summary. http://pubchem. ncbi.nlm.nih.gov/summary/summary.cgi?cid=3339.

59. Bandello F, Cunha-Vaz J, Chong NV, Lang GE, Massin P, Mitchell P, Porta M, Prünte C, Schlingemann R, Schmidt-Erfurth U: New approaches for the treatment of diabetic macular oedema: recommendations by an expert panel. Eye (London) 2012, 26:485-493.

60. Simó R, Hernández C: Intravitreous anti-VEGF for diabetic retinopathy: hopes and fears for a new therapeutic strategy. Diabetologia 2008, $51: 1574-1580$

61. Nicholson BP, Schachat AP: A review of clinical trials of anti-VEGF agents for diabetic retinopathy. Graefes Archive for Clinical and Experimental Ophthalmology 2010, 248:915-930.

62. Abu El-Asrar AM, Al-Mezaine HS: Saudi Journal of Opthalmology 2011, 25:113-122.

63. Mitchell P, Bandello F, Schmidt-Erfurth U, Lang GE, Massin P, Schlingemann RO, Sutter F, Simader C, Burian G, Gerstner O, Weichselberger A: RESTORE study group: The RESTORE study: ranibizumab monotherapy or combined with laser versus laser monotherapy for diabetic macular edema. Ophthalmology 2011, 118:615-625.

64. Nguyen QD, Shah SM, Heier JS, Do DV, Lim J, Boyer D, Abraham P, Campochiaro PA: READ-2 Study Group: Primary End Point (Six Months) Results of the Ranibizumab for Edema of the Macula in Diabetes (READ2) study. Ophthalmology 2009, 116:2175-2181.

doi:10.1186/1471-2415-12-46

Cite this article as: Treacy and Hurst: The case for intraocular delivery of PPAR agonists in the treatment of diabetic retinopathy. BMC Ophthalmology 2012 12:46.

\section{Submit your next manuscript to BioMed Central and take full advantage of:}

- Convenient online submission

- Thorough peer review

- No space constraints or color figure charges

- Immediate publication on acceptance

- Inclusion in PubMed, CAS, Scopus and Google Scholar

- Research which is freely available for redistribution 